NBER WORKING PAPER SERIES

\title{
POLICY DISTORTIONS AND AGGREGATE PRODUCTIVITY WITH ENDOGENOUS ESTABLISHMENT-LEVEL PRODUCTIVITY
}

\author{
José-María Da-Rocha \\ Marina Mendes Tavares \\ Diego Restuccia \\ Working Paper 23339 \\ http://www.nber.org/papers/w23339 \\ NATIONAL BUREAU OF ECONOMIC RESEARCH \\ 1050 Massachusetts Avenue \\ Cambridge, MA 02138 \\ April 2017, Revised April 2023
}

For helpful comments we thank the editor, two anonymous referees, Lukasz Drozd, Sampreet Goraya, Hugo Hopenhayn, Alex Monge-Naranjo, B. Ravikumar, Loris Rubini, and participants at ITAM/INEGI Workshop on Productivity, ITAM, St. Louis Fed, SED Meetings in Toronto, North American Summer Meeting of the Econometric Society in Minneapolis, National Bank of Poland, and Banco de Mexico. All remaining errors are our own. Da Rocha gratefully acknowledges the financial support of Xunta de Galicia (ref. ED431B 2022/03). Restuccia gratefully acknowledges the financial support from the Social Sciences and Humanities Research Council of Canada, the Canada Research Chairs program, and the Bank of Canada Fellowship program. Tavares gratefully acknowledges the financial support of DIFD. The views expressed herein are not necessarily those of the Bank of Canada or the National Bureau of Economic Research and are the author's alone.

NBER working papers are circulated for discussion and comment purposes. They have not been peer-reviewed or been subject to the review by the NBER Board of Directors that accompanies official NBER publications.

(C) 2017 by José-María Da-Rocha, Marina Mendes Tavares, and Diego Restuccia. All rights reserved. Short sections of text, not to exceed two paragraphs, may be quoted without explicit permission provided that full credit, including $\odot$ notice, is given to the source. 
Policy Distortions and Aggregate Productivity with Endogenous Establishment-Level Productivity José-María Da-Rocha, Marina Mendes Tavares, and Diego Restuccia

NBER Working Paper No. 23339

April 2017, Revised April 2023

JEL No. E0,E1,O1,O4

\begin{abstract} the aggregate TFP loss doubles to 48 percent.

José-María Da-Rocha

ITAM

Av. Camino Santa Teresa 930 C.P.

10700 Mexico, D.F

jmrocha@uvigo.es

Marina Mendes Tavares

International Monetary Fund

720 19th Street, NW

Washington, DC 20431

marinamendestavares@gmail.com

Diego Restuccia

Department of Economics

University of Toronto

150 St. George Street

Toronto, ON M5S 3G7

and NBER

diego.restuccia@utoronto.ca
\end{abstract}

What accounts for income per capita and total factor productivity (TFP) differences across countries? We study resource misallocation across heterogeneous production units in a general equilibrium model where establishment productivity and size are affected by policy distortions. We solve the model in closed form and show that policy distortions have a substantial negative effect on establishment productivity growth, average establishment size, and aggregate productivity. Calibrating a distorted benchmark economy to U.S. data, we find that empirically reasonable variations in distortions generate reductions in aggregate TFP of more than 24 percent while slightly increasing concentration in the establishment size distribution. If distortions in addition lower the exit rate of incumbent establishments, as supported by some empirical evidence, 


\section{Introduction}

A crucial question in economic growth and development is why some countries are rich and others poor. A consensus has emerged in the literature whereby the large differences in income per capita across countries are mostly accounted for by differences in labor productivity and in particular total factor productivity (TFP) (Klenow and Rodriguez-Clare, 1997; Prescott, 1998; Hall and Jones, 1999). The question is then: what accounts for differences in TFP across countries? An important channel that has been emphasized is the (mis)allocation of resources across heterogeneous production units. ${ }^{1}$ We study misallocation in a model where establishment-level productivity is influenced by investment decisions of firms, which depend on the policy environment. We show that policy distortions in this framework substantially reduce average establishment size and aggregate productivity.

A recent branch of the literature has emphasized the dynamic implications of misallocation by considering variants of the growth model with producer dynamics. ${ }^{2}$ We build on this literature by developing a general equilibrium model of establishments where the distributions of establishment productivity and size are characterized in closed form as a function of the economic environment which is affected by policy distortions. A key insight of our work arises from exploiting a wellknown property of distorted economies, that establishment size is proportional to distortions and productivity (Restuccia and Rogerson, 2008). Our finding is that variations in policy distortions across economies are mostly reflected in differences in the productivity distribution, generating a substantial drop in aggregate TFP of more than $24 \%$. This finding is connected to a literature documenting power law estimates of firm size distributions across countries (Axtell, 2001; Gabaix, 2009; Luttmer, 2007; di Giovanni and Levchenko, 2013). Moreover, our analytical solution of the

\footnotetext{
${ }^{1}$ See Banerjee and Duflo (2005), Restuccia and Rogerson (2008), Guner et al. (2008), and Hsieh and Klenow (2009). See also the surveys of the literature in Restuccia and Rogerson (2013), Restuccia (2013a), Hopenhayn (2014a), and Restuccia and Rogerson (2017).

${ }^{2}$ Some of the early contributions on the endogenous productivity distribution include Restuccia (2013b), Bello et al. (2011), Acemoglu et al. (2018), Ranasinghe (2014), Bhattacharya et al. (2013), Gabler and Poschke (2013), Rubini (2014), Hsieh and Klenow (2014), Bento and Restuccia (2017), Guner et al. (2018), Peters (2020), Buera and Fattal Jaef (2018), among others. See also Restuccia and Rogerson (2017) for a discussion of this literature.
} 
distribution of productivity and how it is affected by distortions can potentially be useful in empirical applications of dynamic misallocation across countries using panel micro data, an essential issue in the misallocation literature (Restuccia and Rogerson, 2017).

We develop a general equilibrium framework with heterogeneous production units that builds on Hopenhayn (1992) and Restuccia and Rogerson (2008). The framework is a standard neoclassical growth model with production heterogeneity extended to incorporate the dynamic effect of distortions on productivity investment and hence the distribution of establishment-level productivity. The key elements of the model are on the production side. In each period, there is a single good produced in establishments. Establishments are heterogeneous with respect to total factor productivity and have access to a decreasing returns to scale technology with capital and labor as inputs. Establishments are subject to exogenous exit but differently from the standard framework, the distribution of establishment-level productivity is not exogenous, rather it is determined by establishment's investment decisions. In other words, the productivity of establishments is determined endogenously in the model by the properties of the economic environment such as policy distortions. Nevertheless, despite growth in establishment productivity, with exogenous exit, the economy features a stationary distribution of establishments across productivity levels and hence an invariant level of aggregate TFP.

Following the literature, the economy faces policy distortions which, for simplicity, take the form of output taxes on individual producers. That is, each producer faces an idiosyncratic tax and it is the properties of policy distortions that generate misallocation in the model. Revenues collected from these taxes are rebated back to households as a lump-sum transfer. We emphasize that the output distortions we consider are abstract representations, a catch-all for the myriad of implicit and explicit distortions faced by individual producers. While the literature has made substantial progress in identifying the specific policies and institutions that create misallocation, as discussed in Restuccia and Rogerson (2017), the emphasis in our paper is on effect of distortions on the productivity distribution in the economy. As a result, our paper represents a general assessment of the broader consequences of misallocation. 
We provide an analytical solution of this model in continuous time. In particular, we solve in closed form for the stationary distributions of establishment sizes and productivities which are endogenous objects that may vary across economies. We show that the equilibrium productivity distributions are Double Pareto distributions with tail index that depends on policy distortions and on the response of incumbent establishments to distortions when selecting the growth rate of productivity. This allows us to characterize the behavior of aggregate output and TFP across distortionary policy configurations as well as the size and productivity growth rate of establishments, the inequality of the distributions of size and establishment-level productivity, among other statistics of interest.

To explore the quantitative properties of the model, we calibrate the model and provide a set of relevant quantitative experiments. We consider a benchmark economy with distortions that is calibrated to data for the United States. We then perform quantitative analysis by exploring the implications of increasing distortions for aggregate output and TFP under a variety of configurations. Our main result is that increasing distortions substantially reduce the productivity growth rate of establishments, average establishment size, and aggregate TFP, while slightly increasing concentration in the establishment size distribution. If in addition, distortions reduce the exit rate of establishments as supported by some evidence (McKenzie and Paffhausen, 2019), the impact of distortions on aggregate TFP is substantially magnified. These broader effects of distortions on economic outcomes are consistent with cross-country evidence on average establishment sizes (Bento and Restuccia, 2017), with evidence that in more distorted economies the productivity and employment growth of establishments are lower (Hsieh and Klenow, 2014), and with evidence that when distortions are lowered with economic reforms, the productivity growth rate of establishments increases (Pavcnik, 2002; Bustos, 2011).

Our paper is related to a large literature on misallocation and productivity discussed earlier. The literature has emphasized various separate channels such as life-cycle investment of plants, human capital accumulation of managers, experimentation, step-by-step innovation, selection, among many others; and different contexts such as trade and labor policies, financial frictions, and specific sectors. We complement this literature by developing a general model of establishment growth 
featuring a distribution of establishment productivity that can be characterized in closed form. More importantly, our theoretical characterization can be useful in developing methods to estimate the role of dynamic misallocation using panel data of firms, and hence we hope our analysis can facilitate more empirical applications.

Two closely related papers to ours are Hsieh and Klenow (2014) and Bento and Restuccia (2017). Hsieh and Klenow (2014) consider the model of establishment innovation in Atkeson and Burstein (2010) to emphasize the life-cycle growth of establishments and its response to distortions, whereas Bento and Restuccia (2017) emphasize both entry productivity and life-cycle growth. We emphasize three key distinctions with our work. First, in these papers entering establishments draw their productivity from an exogenous and constant distribution across countries, whereas the entire productivity distribution is a key equilibrium object in our framework that responds to policy distortions. Second, we quantify the relevance of changes in the size distribution of firms for the impact of policy distortions on aggregate TFP losses. Third, we differ in the tools used to characterize the economy, in particular, we solve analytically for the entire distribution of productivity using continuous time and Brownian motion processes. These tools are increasingly popular in the growth literature allowing both a tighter theoretical characterization and more efficient computation (e.g., Lucas and Moll, 2014; Benhabib et al., 2014; Buera and Oberfield, 2014). More closely linked, these tools were prominently used in the seminal work of Luttmer (2007) to study the size distribution of establishments in the United States (see also Da-Rocha and Pujolas, 2011; Fattal Jaef, 2018; Gourio and Roys, 2014; Da-Rocha et al., 2019).

The paper proceeds as follows. In the next section, we present the details of the model and section 3 characterizes the equilibrium solution. In section 4 , we characterize aggregate output and TFP and provide a closed-form solution of the model. Section 5 provides a quantitative assessment of the impact of policy distortions on aggregate output, TFP, and other relevant statistics. We conclude in Section 6. 


\section{Economic Environment}

We consider a standard version of the neoclassical growth model with producer heterogeneity as in Restuccia and Rogerson (2008). We extend this framework to allow establishments to invest in their productivity. As as a result, with on-going entry and exit of establishments, the framework generates an invariant distribution of productivity across establishments associated with the economic environment that may differ across countries. Time is continuous and the horizon is infinite. Establishments have access to a decreasing return to scale technology, pay a one-time fixed cost of entry, and exit at an exogenous rate. Establishments hire labor and rent capital services in competitive markets. New entrants enter with a level of productivity which is endogenous. We focus on a stationary equilibrium of this model and study the effects of idiosyncratic policy distortions on the allocation of factors across establishments. In what follows, we provide more details of the economic environment.

\subsection{Baseline Model}

There is an infinity-lived representative household with preferences over consumption goods described by the utility function,

$$
\max \int_{0}^{+\infty} e^{-\varrho t} u(c) d t
$$

where $c$ is consumption and $\varrho$ is the discount rate. The household is endowed with one unit of productive time at each instant and $k_{0}>0$ units of the capital stock at date 0.

The unit of production in the economy is the establishment. Each establishment is described by a production function $f(z, k, n)$ that combines establishment productivity $z$, capital services $k$, and labor services $n$ to produce output. The function $f$ is assumed to exhibit decreasing returns to scale in capital and labor jointly and to satisfy the usual Inada conditions. The production function is 
given by:

$$
y=z^{\theta(1-\alpha-\gamma)} k^{\alpha} n^{\gamma}, \quad \alpha, \gamma \in(0,1), \quad 0<\gamma+\alpha<1, \quad \theta>1
$$

where establishment productivity $z$ is stochastic but establishments can invest in upgrading their productivity at a cost and $\theta$ is a scaling parameter for establishment TFP. Note that establishment

TFP is $z^{\theta(1-\alpha-\gamma)}$ and hence $\theta$ influences the units in which establishment productivity $z$ is measured. Scaling productivity by $\theta$ is convenient for algebraic manipulations of the model as this parameter also represents the curvature in the cost function of establishment productivity growth, but other than the economics of productivity investment, this scaling of productivity is innocuous for the analysis. Establishments also face an exogenous probability of exit $\lambda$.

New establishments can also be created. Entrants must pay an entry $\operatorname{cost} c_{e}$ measured in units of output and as in the literature the expected value of entry satisfies the zero profit condition in equilibrium. Feasibility in the model requires:

$$
C+I+Q=Y-E
$$

where $C$ is aggregate consumption, $I$ is aggregate investment in physical capital, $Q$ is aggregate cost of investing in establishment productivity, $E$ is the aggregate cost of entry, and $Y$ is aggregate output.

\subsection{Policy Distortions}

We introduce policies that create idiosyncratic distortions to establishment-level decisions as in Restuccia and Rogerson (2008). We model these distortions as idiosyncratic output taxes but none of our results are critically dependent on the particular source of distortions. While the policies we consider are hypothetical, there is a large empirical literature documenting the extent of idiosyncratic distortions across countries and our framework allows for a simple mapping between 
distortions and empirical observations (Hsieh and Klenow, 2009; Bartelsman et al., 2013; Restuccia and Rogerson, 2017).

In our framework, distortions not only affect the allocation of resources across existing production units, but also the growth rate of establishment productivity, thereby affecting the distribution of productive units in the economy. Specifically, we assume that each establishment faces its own policy distortion (idiosyncratic distortions) reflected as an output tax rate $\tau_{y}$. In what follows, for convenience we rewrite distortions as $\tau=\left(1-\tau_{y}\right)^{\frac{1}{\theta(1-\alpha-\gamma)}}$. Note that this transformation implies that an establishment with no distortions $\tau_{y}=0$ faces $\tau=1$, whereas a positive output tax $\tau_{y}>0$ implies $\tau<1$ and an output subsidy $\tau_{y}<0$ implies $\tau>1$.

In order to generate dispersion in distortions across productive units, we assume that $\tau$ follows a standard stochastic process, a Geometric Brownian motion,

$$
d \tau=\mu_{\tau} \tau d t+\sigma_{\tau} \tau d w_{\tau}
$$

where $\mu_{\tau}$ is the drift, $\sigma_{\tau}$ is the standard deviation and $d w_{\tau}$ is the standard Wiener process of the Brownian motion. In this specification $\sigma_{\tau}$ controls the dispersion of distortions across producers and hence the dispersion in marginal revenue products.

Establishment's productivity $z$ follows a Geometric Brownian motion and establishments can invest in upgrading their productivity by choosing the drift of the Brownian motion $\mu_{z}$, establishment productivity follows:

$$
d z=\mu_{z} z d t+\sigma_{z} z d w_{z}
$$

where $\sigma_{z}$ is the standard deviation and $d w_{z}$ is the standard Wiener process of the Brownian motion. We assume that the output tax and productivity can be correlated, that is $E\left(d w_{\tau}, d w_{z}\right)=$ $\rho \in(-1,0]$. Note that a negative value of $\rho$, corresponds to the notion of correlated distortions in Restuccia and Rogerson (2008), whereby distortions impact more heavily on more productive establishments. This feature of the environment has been shown to be important in accounting for 
misallocation (e.g., David and Venkateswaran, 2019).

At the time of entry, the entry distortion $\tau_{e}$ is known and establishments enter with a productivity $z_{e}$ that is determined in equilibrium and implies a value of entrants that satisfies the zero profit condition. In this economy, the relevant information for establishment's decisions is the joint distribution over productivity and distortions. We denote this joint distribution by $g(z, \tau)$.

A given distribution of establishment-level distortion and productivity may not lead to a balanced budget for the government. As a result, we assume that budget balance is achieved by either lump-sum taxation or redistribution to the representative household, denoting the lump-sum tax by $T$.

\section{Equilibrium}

We focus on a stationary equilibrium of this economy. The stationary equilibrium is characterized by an invariant distribution of establishments $g(z, \tau)$ over productivity $z$ and distortion $\tau$, a constant entry productivity $z_{e}$, and constant allocation functions. In the stationary equilibrium, the rental price for labor and capital services are also constant and we denote them by $w$ and $r$. Before defining the stationary equilibrium formally, it is useful to consider the decision problems faced by incumbents, entrants, and consumers. We describe these problems in turn.

\subsection{Incumbent establishments}

Incumbent establishments maximize the present value of profits by making static and dynamic decisions. The static problem is to choose the amount of capital and labor services, whereas the dynamic problem involves solving for the establishment productivity drift. We now describe these problems in detail. 
Static problem At any instant of time an establishment chooses how much capital to rent $k$ and how much labor to hire $n$. These decisions are static and depend on the establishment's productivity $z$, the establishment's distortion $\tau$, the rental rate of capital $r$, and the wage rate $w$. Formally, the instant profit function $\pi(z, \tau)$ is defined by:

$$
\pi(z, \tau)=\max _{k, n}(\tau z)^{\theta(1-\alpha-\gamma)} k^{\alpha} n^{\gamma}-w n-r k
$$

from which we obtain the optimal demand for labor and capital:

$$
\begin{aligned}
& n(z, \tau)=\left[\left(\frac{\alpha}{r}\right)^{\alpha}\left(\frac{\gamma}{w}\right)^{1-\alpha}\right]^{\frac{1}{1-\alpha-\gamma}} z^{\theta} \tau^{\theta}, \\
& k(z, \tau)=\left[\left(\frac{\alpha}{r}\right)^{1-\gamma}\left(\frac{\gamma}{w}\right)^{\gamma}\right]^{\frac{1}{1-\alpha-\gamma}} z^{\theta} \tau^{\theta} .
\end{aligned}
$$

For future reference, we redefine instant profits as a function of the optimal demand for factors:

$$
\pi(z, \tau)=m(w, r) z^{\theta} \tau^{\theta}
$$

where $m(w, r)=(1-\alpha-\gamma)\left[\left(\frac{\alpha}{r}\right)^{\alpha}\left(\frac{\gamma}{w}\right)^{\gamma}\right]^{\frac{1}{1-\alpha-\gamma}}$ is a constant across establishments that depends on equilibrium prices. Note that since factor demands are linear in $(z \tau)^{\theta}$, we find it convenient to define size $s$ as $s \equiv(z \tau)^{\theta}$ so that factor demands are proportional to size $s$. A key insight of the misallocation literature is that the relationship between size and productivity is fundamentally affected by distortions. In this setting, distortions put a wedge between factor demands (and revenue) and physical output. Unlike factor demands (as well as revenue and profits), establishment output $y=z^{\theta(1-\alpha-\gamma)} k^{\alpha} n^{\gamma}$ is not a linear function of size. We explicitly derive the relationship between output, distortions, and productivity below.

Dynamic problem Incumbent establishments choose the drift of their productivity $\mu_{z}$. The cost of investing in productivity is expressed in units of output, described by a cost function $q\left(\mu_{z}\right)$ that is 
increasing and convex in the productivity drift. We follow a large literature in innovation and growth by specifying the cost function in units that are proportional to firm's relative revenue (Atkeson and Burstein, 2010; Buera and Fattal Jaef, 2018), but in our framework, revenue is proportional to productivity and distortions which is natural in this context. Specifically, we assume $q\left(\mu_{z}\right)=$ $\left(\frac{c_{\mu} \mu_{z}^{\theta}}{\theta}\right) \frac{z^{\theta} \tau^{\theta}}{\bar{s}}$, where $\theta$ controls the convexity of the cost function and $c_{\mu}$ is a common scale parameter. The cost function is proportional to (relative) establishment size and revenue by a factor $\left(\frac{c_{\mu} \mu_{z}^{\theta}}{\theta}\right)$.

The optimal decision of productivity improvement is characterized by maximizing the present value of profits subject to the Brownian motion governing the evolution of productivity and the Brownian motion governing the evolution of distortions. Formally, incumbent establishments solve the following dynamic problem:

$$
\begin{gathered}
W(z, \tau)=\max _{\mu_{z}}\left\{m(w, r) z^{\theta} \tau^{\theta}-q\left(\mu_{z}\right)+\frac{1}{1+(\lambda+R) d t} E_{z, \tau} W(z+d z, \tau+d \tau)\right\}, \\
\text { s.t. } d z=\mu_{z} z d t+\sigma_{z} z d w_{z}, \\
d \tau=\mu_{\tau} \tau d t+\sigma_{\tau} \tau d w_{\tau},
\end{gathered}
$$

where $\lambda$ is the exogenous exit probability of establishments and $R$ is the stationary equilibrium real interest rate. Next, we define the Hamilton-Jacobi-Bellman of the stationary solution,

$$
\begin{aligned}
(\lambda+R) W(z, \tau)= & \max _{\mu_{z}}\left\{m(w, r) z^{\theta} \tau^{\theta}-\frac{c_{\mu}}{\bar{s}} \frac{\mu_{z}^{\theta}}{\theta} z^{\theta} \tau^{\theta}\right. \\
& \left.+\mu_{z} z W_{z}^{\prime}+\frac{\sigma_{z}^{2}}{2} z^{2} W_{z z}^{\prime \prime}+\mu_{\tau} \tau W_{\tau}^{\prime}+\frac{\sigma_{\tau}^{2}}{2} \tau^{2} W_{\tau \tau}^{\prime \prime}+\sigma_{z} \sigma_{\tau} \rho z \tau W_{z \tau}^{\prime \prime}\right\} .
\end{aligned}
$$

In the following Lemma 1 we characterize formally the endogenous productivity drift.

Lemma 1. Given distortion $\tau$, productivity $z$, and operating profits $m(w, r)$, the value function that solves the establishment dynamic problem is given by $W(z, \tau)=A(w, r) \tau^{\theta} z^{\theta}$ where

$$
A(w, r)=\frac{m(w, r)}{\lambda+R+\mu_{z}-\left[\theta\left(\mu_{\tau}+\mu_{z}\right)+\theta^{2} \sigma_{z} \sigma_{\tau} \rho+\frac{\theta(\theta-1)}{2}\left(\sigma_{z}^{2}+\sigma_{\tau}^{2}\right)\right]},
$$


and the productivity drift

$$
\mu_{z}=\left[\frac{\theta A(w, r) \bar{s}}{c_{\mu}}\right]^{\frac{1}{\theta-1}}
$$

Proof See Appendix A.1.

The implication of Lemma 1 is that the growth rate of productivity of individual establishments is constant and common across establishments, that is, it does not depend on the intrinsic characteristics of the establishment such as productivity $z$ or distortion $\tau$, as a result Gibrat's law holds. We recognize that there is some debate as to whether Gibrat's law holds empirically in developed or less developed countries, however, we note that this implication of the model is more neutral with regards to amplification, that is it implies a more muted negative effect of distortions on output, making our quantitative results conservative in this context. Atkeson and Burstein (2010) develop a model of firm-level innovation with the same property, whereas in Bhattacharya et al. (2013) and Hsieh and Klenow (2014) it holds for undistorted economies but not for distorted economies. While Lemma 1 implies that the endogenous productivity drift is constant across establishments, the drift can differ across economies with different policy distortions when distortions affect equilibrium wages, and this is a key element in our quantitative analysis.

Employment, which is proportional to size $n \propto s=(z \tau)^{\theta}$, also follows Gibrat's law, and the resulting Brownian motion of size implies the following drift:

$$
\mu_{s}=\theta\left(\mu_{z}+\mu_{\tau}+\theta \sigma_{z} \sigma_{\tau} \rho\right)+\theta(\theta-1)\left(\sigma_{z}^{2}+\sigma_{\tau}^{2}\right) / 2 .
$$

In this environment, policy distortions affect productivity growth and employment growth. Employment is impacted by distortions directly through the dispersion of distortions $\sigma_{\tau}$ and its correlation with productivity $\rho$, and indirectly through changes in productivity growth $\mu_{z}(w, r)$. Not only size is not the same as productivity in distorted economies in this framework, but also growth in size is not the same as growth in productivity. 


\section{$3.2 \quad$ Entering establishments}

Potential entering establishments face an entry $\operatorname{cost} c_{e}$ in units of output and make their entry decision knowing the entry distortion $\tau_{e}$. For tractability, we assume that entrants start with the same level of productivity, denoted by $z_{e}$. The initial level of productivity is such that the value of entering establishments satisfies the zero profit condition:

$$
W_{e}=A(w, r)\left(\tau_{e} z_{e}\right)^{\theta}-c_{e}=A(w, r) s_{e}-c_{e}=0 .
$$

Note that such a value of productivity $z_{e}$ exists and is unique which follows from the fact that the value of entry $W_{e}$ inherits the properties of the value of incumbent establishments which is increasing in productivity $z_{e}$. In addition, in the special case where the model is deterministic, the value of entry is the same as in Restuccia and Rogerson (2008), which is the discounted value of establishments' profit.

For simplicity, we assume that the mass of establishments is exogenous and normalized to one. We extend the model to allow for an endogenous mass of establishments in Appendix B and show that the qualitative and quantitative implications are robust to this extension. In particular, the model with endogenous mass of establishments mitigates the impact of policy distortions on aggregate TFP as typically found in the related literature, but the quantitative effect in our context is relatively small.

\subsection{Stationary distribution of establishments}

Given the optimal decisions of incumbents and entering establishments, we are now ready to characterize the stationary distribution $g(z, \tau)$ over productivity $z$ and distortion $\tau$. The first step to characterize this distribution is to rewrite the Brownian motions of productivity $z$ and distortion $\tau$ as a function of size $s$. In order to characterize the stationary distribution over size, it is useful to rewrite the model in logarithms. Let $x$ denote the logarithm of relative size, that is $x=\log \left(s / s_{e}\right)$, 
where $s_{e}=\left(\tau_{e} z_{e}\right)^{\theta}$ is the size in which establishments enter. Now we can rewrite the Geometric Brownian motion of $x$ as

$$
d x=\mu_{x} d t+\sigma_{x} d w_{x}
$$

where

$$
\mu_{x}=\theta\left(\mu_{z}+\mu_{\tau}\right)+\frac{\theta(\theta-1)}{2}\left(\sigma_{z}^{2}+\sigma_{\tau}^{2}\right)-\frac{\theta^{2}}{2}\left(\sigma_{z}^{2}+\sigma_{z}^{2}\right)
$$

and

$$
\sigma_{x}^{2}=\theta^{2}\left(\sigma_{z}^{2}+\sigma_{\tau}^{2}+2 \sigma_{z} \sigma_{\tau} \rho\right)
$$

We use the Kolmogorov-Fokker-Planck (KFP) equation to characterize the stationary distribution of $x$ :

$$
\frac{\partial f(x, t)}{\partial t}=-\mu_{x} \frac{\partial f(x, t)}{\partial x}+\frac{\sigma_{x}^{2}}{2} \frac{\partial^{2} f(x, t)}{\partial x^{2}}-\lambda f(x, t)+b(0, t)
$$

where $\lambda$ is the exogenous exit rate of establishments, $b(0, t)$ is the measure of establishments that enter at time $t$ and have size 0 , after the normalization. The solution of this problem is discussed in Gabaix (2009). We are interested in solving for the steady state where $f(x, t)=f(x)$ and $b(0, t)=b(0)$. Therefore, we can rewrite the KFP equation (11) as:

$$
f^{\prime}(x)=-\mu_{x} f^{\prime}(x)+\frac{\sigma_{x}^{2}}{2} f^{\prime \prime}(x)-\lambda f(x)+b \delta(x-0)=0
$$

and we assume four boundary conditions:

$$
\begin{array}{ll}
\lim _{x \rightarrow-\infty} f(x)=0, & \lim _{x \rightarrow+\infty} f(x)=0, \\
\lim _{x \rightarrow-\infty} f^{\prime}(x)=0, & \lim _{x \rightarrow+\infty} f^{\prime}(x)=0,
\end{array}
$$

and that $f(\cdot)$ is a $p . d . f$, i.e. $f(x) \geq 0$ and $\int_{-\infty}^{+\infty} f(x) d x=1$. The first two boundary conditions (13) guarantee that the stationary distribution is bounded, whereas the next two boundary conditions (14) imply that $b$ is equal to $\lambda$, that is, the stationary equilibrium entry rate is equal to the exogenous 
exit rate. ${ }^{3}$ We can now characterize the stationary $(\log )$ size distribution, which is a double Pareto. Formally, Lemma 2 characterizes the stationary distribution.

Lemma 2. Given wages $w$, rental rate of capital $r$, and a policy $\left(\tau_{e}, \mu_{\tau}, \sigma_{\tau}, \rho\right)$ the stationary size distribution is a double Pareto:

$$
g(s)=\left\{\begin{array}{l}
C\left(\frac{s}{s_{e}}\right)^{-\left(\xi_{s}^{-}+1\right)} \quad \text { for } s<s_{e} \\
C\left(\frac{s}{s_{e}}\right)^{-\left(\xi_{s}^{+}+1\right)} \quad \text { for } s \geq s_{e} .
\end{array}\right.
$$

where the tail index $\xi_{s}^{+}$is the positive root and the tail index $\xi_{s}^{-}$is the negative root that solves the characteristic equation

$$
\frac{\sigma_{x}^{2}}{2} \xi^{2}+\left(\mu_{s}-\frac{\sigma_{x}^{2}}{2}\right) \xi-\lambda=0
$$

and $C=\frac{-\xi_{s}^{-} \xi_{s}^{+}}{s_{e}\left(\xi_{s}^{+}-\xi_{s}^{-}\right)}$. Moreover, average establishments size $\bar{s}$ is given by:

$$
\bar{s}=\left(\frac{\lambda}{\lambda-\mu_{s}}\right) s_{e} .
$$

Proof See Appendix A.2.

We leave the poof of Lemma 2 to the Appendix. Lemma 2 characterizes the endogenous distribution as a function of establishments' size drift $\mu_{s}$ and entry size $s_{e}$, which in turn are affected by distortions. Using the same methodology as in Lemma 2, we can solve for the distributions of productivity and distortions (the equilibrium values of $\xi_{z}$ and $\xi_{\tau}$ ). The boundary conditions on

\footnotetext{
${ }^{3}$ Integrating (12) we obtain:

$$
\int_{\infty}^{+\infty} f^{\prime}(x) d x=\left.\left(-\mu_{x} f(x)+\frac{\sigma_{x}^{2}}{2} f^{\prime}(x)\right)\right|_{-\infty} ^{+\infty}-\lambda \int_{-\infty}^{+\infty} f(x) d x+\int_{-\infty}^{+\infty} b \delta(x-0) d x=0
$$

and applying the boundary conditions and using the Dirac delta function, $\int_{-\infty}^{+\infty} \delta(x-0) d x=1$, results in $b=\lambda$.
} 
these distributions prevent establishments with negative values of productivity $z$ and distortions $\tau$.

\subsection{Household's problem}

The household problem essentially help us pin down the stationary real interest rate $R$. As such, the process for capital accumulation in this model follows the standard neoclassical growth model. The stand-in household seeks to maximize lifetime utility subject to the law of motion of wealth given by:

$$
\left(R K+w+T+\Pi-b c_{e}-c\right) d t
$$

where $w$ is the wage rate, $R$ is the interest rate which in equilibrium is the rental price of capital minus capital depreciation $\left(R=r-\delta_{k}\right), T$ is the lump-sum tax levied by the government, $\Pi$ is the total profit from the operation of all establishments, $b c_{e}$ is the total entry cost of establishments and $c$ is consumption.

We assume that households have $\log$ utility, $u(c)=\log (c)$. The solution of this problem is standard and implies that $R=\varrho$. In the stationary equilibrium, aggregate consumption $C$ and physical capital $K$ are constants.

\subsection{Stationary equilibrium}

Definition Given a policy $\left\{\mu_{\tau}, \sigma_{\tau}, \rho, \tau_{e}\right\}$, a stationary equilibrium is an invariant size distribution $g(s)$, value and policy functions of incumbent establishments $W(s), k(s), n(s)$, establishment productivity growth $\mu_{z}$, value of entrants $W_{e}$, entrants' productivity $z_{e}$, entry rate $b$, prices $(r, w)$, transfer $T$, profits $\Pi$, capital $K$, and consumption $C$, such that:

i) Consumer optimization implies that $R=r-\delta_{k}=\varrho$ and aggregates $C$ and $K$.

ii) Given prices, the incumbents' policy functions $\{k(s), n(s)\}$ solve the incumbents' static prob$\operatorname{lem}(2)$. 
iii) Given prices, the incumbents' value function $W(s)$ solves the incumbents' dynamic problem (6), $\mu_{z}$ is optimal from this problem.

iv) Given prices, the value of entrants satisfy the zero profit condition in (B.3) and entry productivity $z_{e}$ is determined by this condition.

v) The stationary distribution $g(s)$ and entry rate of establishments $b$ solve the KolmogorovFokker-Planck equation (11).

vi) Markets for capital and labor clear (market clearing in the goods market is satisfied by Walras' law):
a) capital: $K=\int_{0}^{+\infty} k(s) g(s) d s$
b) labor: $1=\int_{0}^{+\infty} n(s) g(s) d s$

vii) Transfers $T$ guarantee that the government's budget constraint is satisfied.

\section{Aggregate Output and Productivity}

Aggregate output $Y$ is obtained by integrating over the distribution of establishment's output. From the establishment production function in equation (1), we substitute the demand for labor and capital in equations (3) and (4), and use the labor market clearing condition to substitute for the wage to obtain:

$$
y(z, \tau)=\left(\frac{\alpha}{r}\right)^{\frac{\alpha}{1-\alpha}}\left(\frac{1}{\bar{s}}\right)^{\frac{\gamma}{1-\alpha}} \tau^{\theta(\alpha+\gamma)} z^{\theta} .
$$

Given that $y \propto \tau^{\theta(\alpha+\gamma)} z^{\theta}$ is a Brownian motion, the output drift is equal to

$$
\mu_{y}=\mu_{\tau^{\theta(\alpha+\gamma)} z^{\theta}}=\theta \mu_{z}+\theta(\theta-1) \sigma_{z}^{2} / 2+(\alpha+\gamma)\left\{\theta \mu_{\tau}+\theta^{2} \rho \sigma_{z} \sigma_{\tau}+\left[\theta^{2}(\alpha+\gamma)-\theta\right] \sigma_{\tau}^{2} / 2\right\}
$$

After integrating, using the same methodology as in Lemma 2, and rearranging terms we write 
aggregate output $Y$ and total factor productivity $Y / K^{\alpha}$ as: ${ }^{4}$

$$
\begin{aligned}
Y & =\left(\frac{\alpha}{r}\right)^{\frac{\alpha}{1-\alpha}}\left(\frac{\lambda-\mu_{s}}{\lambda-\mu_{y}}\right) \bar{s}^{\frac{1-\alpha-\gamma}{1-\alpha}}\left(\frac{1}{\tau_{e}^{\theta(1-\alpha-\gamma)}}\right), \\
\mathrm{TFP} & =\left(\frac{\lambda-\mu_{s}}{\lambda-\mu_{y}}\right) \bar{s}^{1-\alpha-\gamma}\left(\frac{1}{\tau_{e}^{\theta(1-\alpha-\gamma)}}\right) .
\end{aligned}
$$

Recalling that in undistorted economies the productivity, size and output drifts are all the same, these equations highlight the relevance of distortions in driving a wedge between the output and size drifts in distorted economies which lowers aggregate TFP. In particular, note that in this framework aggregate output and productivity may be lower with policy distortions not only through their effects on average establishment size $\bar{s}$, but also by the wedge between size and output drifts. These drifts determine average size and output relative to entry and their underlined distributions.

Model solution. We can easily solve for the stationary equilibrium. First, the stationary rental rate of capital $r$ is pin down by $\varrho$ and $\delta_{k}$ from the household problem in steady state. Second, we solve a non-linear system of five equations in five unknowns $\left\{z_{e}, \mu_{z}, \mu_{s}, \bar{s}, A\right\}$ as follows:

(1) The free entry condition:

$$
A\left(\tau_{e} z_{e}\right)^{\theta}=c_{e}
$$

(2) The productivity growth rate $\mu_{z}$ :

$$
\mu_{z}=\left[\frac{\theta A \bar{s}}{c_{\mu}}\right]^{\frac{1}{\theta-1}} .
$$

\footnotetext{
${ }^{4}$ Aggregate capital is given by integrating equation (4) over establishment size,
}

$$
K=\left(\frac{\alpha}{r}\right)^{\frac{1}{1-\alpha}} \bar{s}^{\frac{1-\alpha-\gamma}{1-\alpha}}=\left(\frac{\alpha}{r}\right)^{\frac{1}{1-\alpha}}\left[\left(\frac{\lambda}{\lambda-\mu_{s}}\right)\left(\tau_{e}^{\theta} z_{e}^{\theta}\right)\right]^{\frac{1-\alpha-\gamma}{1-\alpha}} .
$$


(3) The size growth rate,

$$
\mu_{s}=\theta \mu_{z}+\theta(\theta-1) \sigma_{z}^{2} / 2+\theta \mu_{\tau}+\theta(\theta-1) \sigma_{\tau}^{2} / 2+\theta^{2} \rho \sigma_{z} \sigma_{\tau}
$$

(4) The relative incumbent to entry size:

$$
\frac{\bar{s}}{\left(\tau_{e} z_{e}\right)^{\theta}}=\left(\frac{\lambda}{\lambda-\mu_{s}}\right)
$$

which given the labor market clearing condition implies the wage rate $w=\gamma\left(\frac{\alpha}{r}\right)^{\frac{\alpha}{1-\alpha}} \bar{s}^{\frac{1-\alpha-\gamma}{1-\alpha}}$.

(5) The establishment's value to size ratio $A$ is:

$$
A=\frac{(1-\alpha-\gamma)}{\left(\lambda+R+\mu_{z}-\mu_{s}\right)}\left(\frac{\alpha}{r}\right)^{\frac{\alpha}{(1-\alpha)}}\left(\frac{1}{\bar{s}}\right)^{\frac{\gamma}{1-\alpha}}
$$

Note that this system has a closed-form solution. From the free entry condition in equation (19), we substitute $A$ in equation (20) and use the relative incumbent to entry size condition in equation (22) to substitute for $\bar{s} /\left(\tau_{e} z_{e}\right)^{\theta}$ and obtain the equilibrium condition between productivity and size growth rates:

$$
\mu_{z}=\left[\frac{\theta c_{e}}{c_{\mu}}\left(\frac{\lambda}{\lambda-\mu_{s}}\right)\right]^{\frac{1}{\theta-1}}
$$

Using $\mu_{s}$ from equation (21), we obtain the solution for the productivity growth rate:

$$
\theta \mu_{z}^{\theta}-\mu_{z}^{\theta-1}\left[\lambda-\theta(\theta-1) \sigma_{z}^{2} / 2-\theta \mu_{\tau}-\theta(\theta-1) \sigma_{\tau}^{2} / 2-\theta^{2} \rho \sigma_{z} \sigma_{\tau}\right]+\lambda \theta \frac{c_{e}}{c_{\mu}}=0
$$


Given the solution for $\mu_{z}$ we can solve sequentially for all the other equilibrium variables as follows:

$$
\begin{aligned}
\mu_{s} & =\theta \mu_{z}+\theta(\theta-1) \sigma_{z}^{2} / 2+\theta \mu_{\tau}+\theta(\theta-1) \sigma_{\tau}^{2} / 2+\theta^{2} \rho \sigma_{z} \sigma_{\tau} \\
\bar{s}^{\frac{1-\alpha-\gamma}{1-\alpha}} & =\left(\frac{\lambda c_{e}}{\bar{m}(r)}\right)\left[\frac{\lambda+R-\mu_{s}+\mu_{z}}{\lambda-\mu_{s}}\right], \\
s_{e} & =\left(1-\frac{\mu_{s}}{\lambda}\right) \bar{s}, \\
z_{e} & =s_{e}^{1 / \theta} / \tau_{e} .
\end{aligned}
$$

The equilibrium values of $\mu_{s}$ and $s_{e}$ can be used to solve for the size distribution in the economy using Lemma 2, in particular, the tail index $\xi_{s}^{+}$is the positive root solution from the characteristic equation (16). Hence, $\xi_{s}^{+}$is the positive root that solves the characteristic equation:

$$
\frac{\theta^{2}\left(\sigma_{z}^{2}+\sigma_{\tau}^{2}+2 \sigma_{z} \sigma_{\tau} \rho\right)}{2} \xi_{s}^{2}+\left(\mu_{s}-\frac{\theta^{2}\left(\sigma_{z}^{2}+\sigma_{\tau}^{2}+2 \sigma_{z} \sigma_{\tau} \rho\right)}{2}\right) \xi_{s}-\lambda=0
$$

What is the quantitative impact of distortions on aggregate productivity in this framework? We answer this question in the next section by calibrating a distorted benchmark economy to U.S. data and conducting counterfactual experiments on the extent of policy distortions.

\section{Quantitative analysis}

We assess the quantitative impact of policy distortions on aggregate output and productivity. An important feature of our analysis is to highlight the effect of policy distortions on establishment's growth and aggregate productivity.

Calibration. We calibrate a benchmark economy with distortions to U.S. data and then study the impact of alternative hypothetical policy distortions in the same spirit of Restuccia and Rogerson (2008). We start by selecting a set of parameters that are standard in the literature. These parameters have either well-known targets, which we match, or the values have been well discussed 
in the literature. Following the literature, we assume decreasing returns in the establishment-level production function and set $\alpha+\gamma=0.85$ (Restuccia and Rogerson, 2008). Then we split it between $\alpha$ and $\gamma$ by assigning $1 / 3$ to capital and $2 / 3$ to labor, implying $\alpha=0.283$ and $\gamma=0.567$. We set the discount rate $\varrho$ to match a real interest rate of 4 percent and the depreciation rate of capital $\delta$ to 7 percent to match a capital to output ratio of 2.5 . We normalize $\tau_{e}=1\left(\tau_{y, e}=0\right)$ and keep it constant across all economies. For the benchmark economy we set $\rho=-0.09$ based on the near zero elasticity between distortions and productivity in U.S. manufacturing (Hsieh and Klenow, 2009, 2014).

We then solve the stationary equilibrium and select the following 6 parameters to match 6 moments from the U.S. data. We select $c_{\mu}$ to match the establishment productivity growth rate of $4 \%$ $\left(\mu_{z}=0.04\right)$ from Hsieh and Klenow (2014); $\theta$ to match the establishment output growth rate of $5 \%\left(\mu_{y}=0.05\right)$ from Hsieh and Klenow $(2014) ; \sigma_{z}^{2}$ and $\lambda$ are selected to match an exit rate of $10 \%$ in line with estimates in the literature (e.g., Davis et al., 1998) and the positive root of the employment size distribution of $1.059\left(\xi_{s}^{+}=1.059\right)$ from Axtell $(2001) ; \sigma_{\tau}^{2}$ to match the standard deviation of the log of TFPR (see Appendix A.3) of 0.49 (Hsieh and Klenow, 2009); $\mu_{\tau}$ to normalize mean distortions to 1 (mean $\left.\tau^{\theta}=1\right)$; and $c_{e}$ to match an average establishment size $\bar{s}=21.85$ (Bento and Restuccia, 2017). Parameter values and moments are summarized in Table 1.

Table 1: Calibration of Benchmark Economy

\begin{tabular}{lclc}
\hline Parameter & Value & Target & Value \\
\hline$c_{\mu}$ & 95.06 & Establishment productivity growth rate & 0.04 \\
$\theta$ & 1.80 & Establishment output growth rate & 0.05 \\
$\sigma_{z}^{2}$ & 0.0390 & Positive root size distribution $\left(\xi_{s}^{+}\right)$ & 1.059 \\
$\lambda$ & 0.10 & Exit rate & 0.10 \\
$\sigma_{\tau}^{2}$ & 0.1492 & SD log TFPR & 0.49 \\
$\mu_{\tau}$ & -0.0597 & Normalized, mean $\tau^{\theta}$ & 1.00 \\
$c_{e}$ & 0.8937 & Average size $(\bar{s})$ & 21.85 \\
\hline
\end{tabular}


Experiments. We study the impact of policy distortions on establishment-level productivity, aggregate output, aggregate TFP, and other relevant variables by comparing statistics in more distorted economies than in the benchmark economy. We study the impact of changes in policy distortions by considering economies that are relatively more distorted than the benchmark economy via changes in the dispersion of distortions $\sigma_{\tau}$. We consider variations in $\sigma_{\tau}$ within the range of estimates in the empirical literature (e.g., Hsieh and Klenow, 2009; Buera et al., 2013; Bento and Restuccia, 2017; Cirera et al., 2020; Restuccia and Rogerson, 2017). While we have witnessed a tremendous increase in firm-level data availability around the world, access to these data and comparisons of samples across countries remain a challenge. For this reason, we find it useful to consider hypothetical economies to study the broad dynamic effects of misallocation. These experiments are not meant to represent any individual country but instead provide an assessment of the role of distortions on establishment-level productivity and aggregate output in our framework relative to standard analyses of static factor reallocation.

We document our quantitative results in Figure 1 by reporting equilibrium values of the productivity drift $\mu_{z}$, average size $\bar{s}$, aggregate TFP, entry size, and power law estimates relating to the establishment's distribution of TFP and size.

Figure 1, blue-solid line, reports the results of increases in distortions in the benchmark economy. The standard deviation of log revenue productivity in the most distorted economy we consider is only about 10 percent larger than in the benchmark economy. We highlight the following changes. Establishment productivity growth declines substantially by almost half, from $4 \%$ in the benchmark economy to $2.1 \%$ in the most distorted economy. Larger distortions also reduce average establishment size, from 21.9 workers in the benchmark economy to 1.7 in the most distorted economy, broadly in line with the variation observed in establishment sizes across countries (Bento and Restuccia, 2021). These changes in the size and productivity distribution of establishments imply a drop in aggregate TFP of more than $24 \%$. This effect on aggregate TFP is much larger in our dynamic framework compared with an environment with constant productivity distribution. In this regard, note that typical analysis of misallocation, such as that in Hsieh and Klenow (2009), treats 
Figure 1: Effects of Changes in Policy Distortions $\sigma_{\tau}^{2}$ by Factor $\Delta$
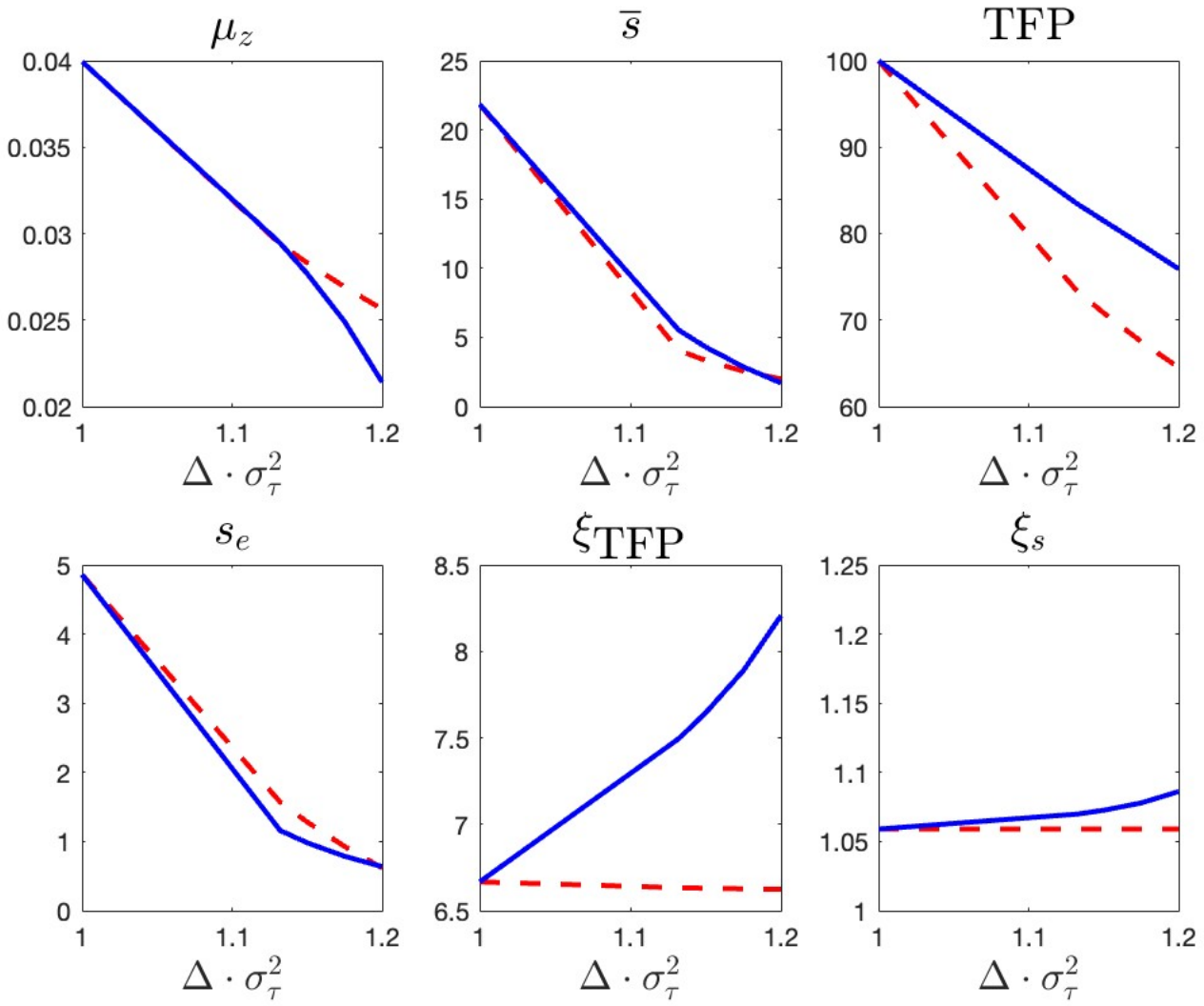

Notes: The blue-solid line represents the benchmark economy with changes in $\sigma_{\tau}^{2}$ by factor $\Delta$ (baseline). The reddashed line represents the same economies but restricting $\xi_{s}^{+}$constant (by adjusting $\lambda$ ) and mean distortions constant ( $\mu_{\tau}$ adjusted to normalize mean distortions to one $\tau^{\theta}=1$ ).

aggregate factors as given including the number of firms. As such, the productivity distribution and average establishment size are always constant. The effect on average size is an important component of the larger effect of misallocation in our framework, as average size directly impacts aggregate TFP (see equation 18). The quantitative effect of average size differences on aggregate TFP is quite substantial, accounting for most of the reduction in aggregate TFP. We also note that even though more distorted economies have more dispersed distortions, the distribution of productivity growth and relative employment are relatively more compressed (higher $\xi$ in the last two panels).

The increase in distortions via increasing $\sigma_{\tau}$ produces two effects. First, average distortions increase 
(e.g., mean $\tau^{\theta}$ increases by 27 percent in the most distorted economy relative to the benchmark economy) and second, the distribution of employment across establishments features more concentration $\left(\xi_{s}^{+}\right.$increases from 1.059 to 1.086$) .{ }^{5}$ To assess the importance of these changes, we quantify the effects of the same increases in $\sigma_{\tau}$ holding both $\xi_{s}^{+}$and mean distortions constant. Note that mean $\tau^{\theta}=1$ implies that $\theta \mu_{\tau}+\theta(\theta-1) \sigma_{\tau}^{2} / 2=0$ and hence we adjust $\mu_{\tau}$ when changing $\sigma_{\tau}$. To keep the endogenous relative size distribution with $\xi_{s}^{+}$constant to the level calibrated in the benchmark economy, we adjust the exit rate of establishments $\lambda$ using the detailed characteristic equation. In particular, recall that the distribution of relative sizes (equation 15), satisfies the characteristic equation (16), hence, using equations (8) and (10), we write $\lambda$ as:

$$
\lambda=\theta \xi_{s}^{+}\left\{\mu_{z}+\mu_{\tau}+\left(\xi_{s}^{+} \theta-1\right)\left(\sigma_{z}^{2}+\sigma_{\tau}^{2}\right) / 2+\theta \xi_{s}^{+} \rho \sigma_{z} \sigma_{\tau}\right\}
$$

Note that the firm (log) size distribution satisfies (Gabaix, 2009), $-\xi_{s}^{-} \xi_{s}^{+}=2 \lambda / \sigma_{x}^{2}$., therefore (other things equal), the tail index product $-\xi_{s}^{-} \xi_{s}^{+}$is lower in economies with lower exit rates $\lambda$.

Using equation (31) to solve for $\lambda$ that keeps $\xi_{s}^{+}$constant to the level in the benchmark economy, we find that lower $\lambda$ 's are required in more distorted economies, from $10 \%$ in the benchmark economy to $7.3 \%$ in the most distorted economy. We report the results of these economies in the red-dashed line in Figure 1. While the effect of distortions on the productivity growth of establishments and average establishment size are relatively similar, the impact on aggregate TFP is much larger when $\xi_{s}^{+}$is kept constant, that is when $\lambda$ is lower and the establishment's lifespan is longer. The aggregate TFP loss in the most distorted economy is more than $35 \%$ compared with $24 \%$ in the baseline. This larger effect on aggregate TFP arises because of the fatter tail in the distribution of establishment TFP associated with longer establishment's lifespans.

To further understand the role of the size distribution via changes in establishment's lifespan $\lambda$, we quantify alternative distorted economies where mean distortions are kept constant but rather than adjusting $\lambda$ to keep $\xi_{s}^{+}$constant, we change $\lambda$ to match the same relative size distribution pa-

\footnotetext{
${ }^{5} \mathrm{We}$ also note that the value for the left tail index of the relative size distribution in the benchmark economy is $\xi_{s}^{-}-=-0.3341$ and the number of "small firms" (the density of $s<s_{e}$ ) increases in more distorted economies.
} 
rameter $\xi_{s}^{+}$as in the baseline economies. These alternative economies highlight the importance of establishment's lifespan for aggregate TFP losses. Figure 2 reports the results with the alternative economies in the red-doted-dashed line. Relative to the baseline economies, the red-doted-dashed line economies have no changes in mean distortions but a larger change in $\lambda$ to attain the same relative size distribution as in the baseline. The larger lifespan implies that distortions produce a larger negative effect on productivity growth, a larger effect on establishment size and a larger negative effect on aggregate TFP. Correspondingly, we conclude that if distortions are accompanied with longer establishment's lifespans, then distortions produce even larger losses on aggregate TFP. This result complements the analysis in Hopenhayn (2014b) where information on the size distribution alone is not sufficient to assess the impact of policy distortions on aggregate outcomes.

The effect of policy distortions on aggregate TFP is quantitatively large in our framework because it not only affects the allocation of resources across establishments, but also because it affects establishment's productivity growth and hence the distribution of establishment's productivity. This is the case even when $\lambda$ is kept constant. What does the evidence indicate regarding establishment's lifespan and the relative firm size distribution between developed and less developed countries? On firm exit, there is limited evidence due to the fact that a serious analysis of firm exit requires substantial amounts of data across countries, not only to capture countries at different levels of development, but also panel data long enough to accurately reflect the exit rate of firms. Despite this data limitation, McKenzie and Paffhausen (2019) provide an analysis of firm death rates from sixteen panel surveys that allow estimation of firm exit over horizons as short as three months and as long as seventeen years. The main finding is that exit rates of firms are larger for richer countries. Quantitatively, a one log point higher GDP per capita is associated with a significant 5.3 percent higher annualized firm death rate.

Our quantitative analysis provides an assessment of the extent to which constant or more concentrated size distribution of firms matters for aggregate TFP losses. The empirical evidence on the size distribution of firms suggests a relatively narrow range of power law estimates. The most comprehensive evidence across countries is provided in di Giovanni and Levchenko (2013) using 
Figure 2: Effects of Changes in Policy Distortions in Alternative Economies
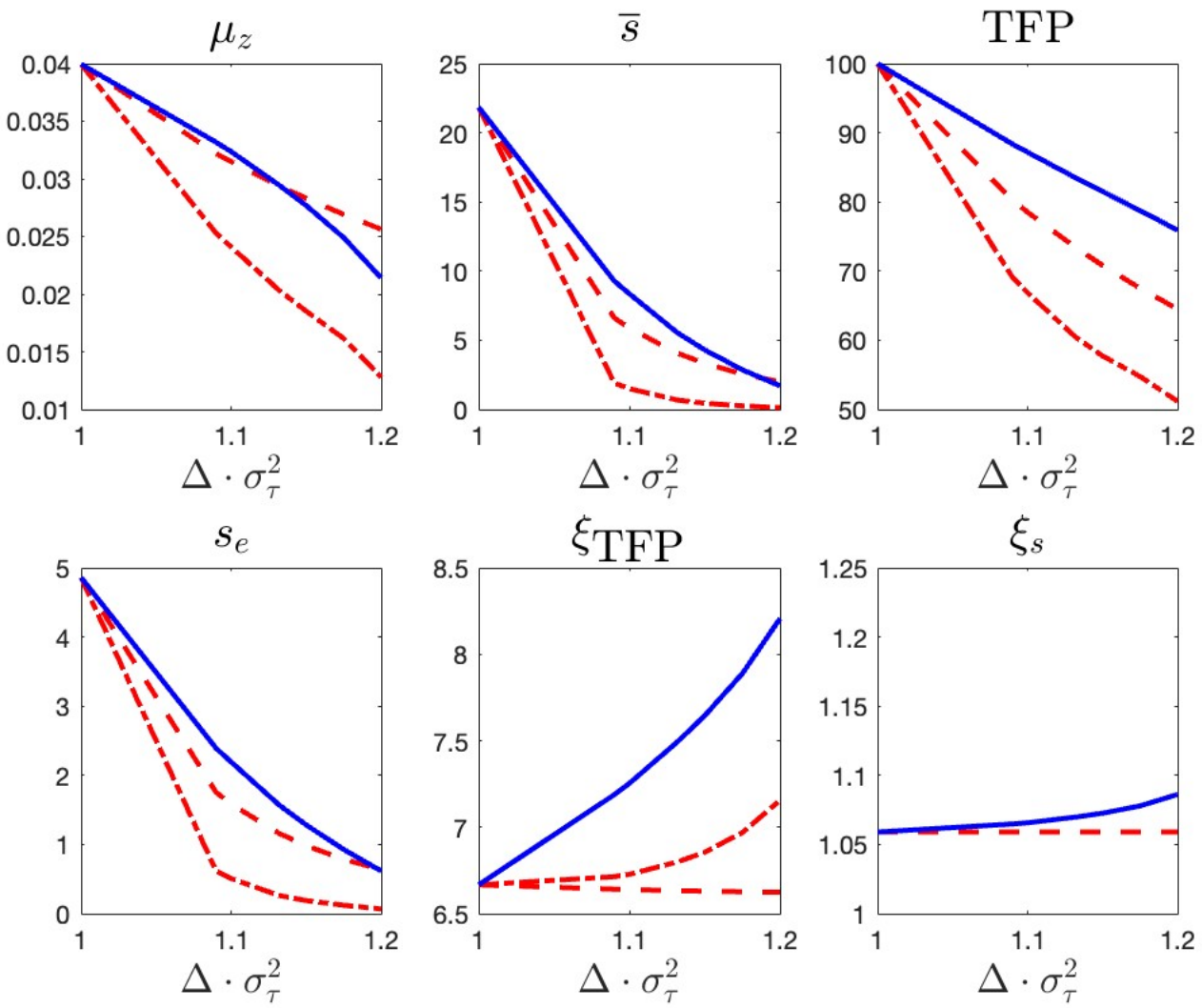

Notes: The blue-solid line represents the benchmark economy with changes in $\sigma_{\tau}^{2}$ by factor $\Delta$ (baseline). The reddashed line represents baseline economies but restricting $\xi_{s}$ constant (by adjusting $\lambda$ ) and mean distortions constant ( $\mu_{\tau}$ adjusted to normalize mean distortions to one $\tau^{\theta}=1$ ). The red-dotted-dashed line represents baseline economies but with mean distortions constant and $\lambda$ adjusted to attain the same $\xi_{s}$ as in baseline economies.

cross-country firm-level data from ORBIS. The estimates for a sample of 44 countries around the world are consistent with a power law providing a good fit of the size distribution and power law coefficients that are quite close to one, similar to that found for the United States by Axtell (2001). Of course, cross-country comparability of data samples is an issue and in fact Tybout (2014) reports a higher power law coefficient of the size distribution in India (1.45) compared to the United States (1.03). Similarly, Hopenhayn (2014b) emphasizes that when conditioning on average size, the normalized size distribution in China appears quite similar to that in the United States, whereas Mexico and India are similar to each other but more compressed than that of the United States. This tentative evidence suggest that relative size distributions are fairly similar across countries, 
perhaps slightly more compressed distributions in developing countries as produced by our baseline experiment.

We now study the importance of $\rho$ in our analysis. To illustrate the effects, we first exploit our analytical characterization under some simplifying assumptions. Following Axtell (2001) and Gabaix (2009), we can characterize analytically the impact of distortions on the productivity drift by focusing on economies satisfying Zipf's law (for a more general discussion of power laws in economics, see Gabaix, 2016). Recall that the distribution of relative sizes (equation 15), satisfies the characteristic equation (16). Using equations (8) and (10), we rewrite the characteristic equation (16) as in equation 31. Given $\mu_{z}$ in equation (25), we use equation (31) to substitute for $\lambda$, and taking the limit $\xi_{s}^{+} \rightarrow 1$ (Zipf's law) we have $\theta \frac{c_{e}}{c_{\mu}} \rightarrow 0$. In this context, Zipf's law implies $\lambda \rightarrow 0$ (see also Gabaix, 2016) and the associated productivity drift is given by:

$$
\mu_{z}=-\left[\mu_{\tau}+(\theta-1) \sigma_{\tau}^{2} / 2\right]-\left[\theta \rho \sigma_{\tau} \sigma_{z}+(\theta-1) \sigma_{z}^{2} / 2\right]
$$

We can use this expression to derive the change in the productivity drift $\mu_{z}$ from changes in distortions $\left(\sigma_{\tau}, \rho\right)$ :

$$
\frac{d \mu_{z}}{d \sigma_{\tau}}=-\left[(\theta-1) \sigma_{\tau}+\theta \rho \sigma_{z}\right]
$$

Given that $\theta>1$, the main insight from this expression is that productivity growth is lower in more distorted economies (higher $\sigma_{\tau}$ ). We also note that with negative correlation $(\rho<1)$, dispersion in $\tau$ and $z$ have opposite effects on productivity growth. An implication of this result is that $\rho=-1$ provides the lowest impact of distortions on productivity growth. This is relevant in the context of the misallocation literature since assuming that $\tau=z^{-\nu}$ (e.g., Hsieh and Klenow, 2014; Bento and Restuccia, 2017; Buera and Fattal Jaef, 2018), implies in our model that $\rho=-1$ and that the dispersion in distortions is affected by changes in $\nu\left(\sigma_{\tau}^{2}=\nu^{2} \sigma_{z}^{2}\right)$.

To illustrate this effect quantitatively in the general case, we compare the aggregate TFP loss of 
distortions in the baseline experiment with a distorted economy that has a one percentage point larger $\rho$ (more negative $\rho$ ). Whereas in the baseline experiment the aggregate TFP loss of distortions is $24 \%$, in the larger $\rho$ economy is $20 \%$.

\section{Conclusions}

We develop a tractable dynamic model of heterogeneous producers to study the effect of distortions on the distribution of establishment-level productivity across economies. The model tractability allows us to obtain closed-form solutions that are useful in identifying the response of distortions on aggregate output. We show that policy distortions have substantial negative effects on aggregate output and TFP in this economy compared to the existing literature.

It would be interesting to explore specific policies and institutions - such as size-dependent policies, firing taxes, financial frictions - in the context of our framework with dynamic effects of distortions (see for example, Da-Rocha et al., 2019; Aghion et al., 2021). These explorations of specific policies in our framework may help reconcile the empirically large effects found in the literature. As a result, further progress aimed at broadening the empirical mapping of the model to the data may provide useful insights. Our analytical solution of the productivity distribution as a function of distortions is a critical first step in this mapping. But the mapping requires reliable and comparable panel data of producers across countries. While these data are increasingly available for some countries, comparability across countries remains an important limitation. We leave these interesting and important explorations for future work. 


\section{References}

Acemoglu, D., Akcigit, U., Alp, H., Bloom, N., and Kerr, W. (2018). Innovation, reallocation, and growth. American Economic Review, 108(11):3450-91.

Aghion, P., Bergeaud, A., and Van Reenen, J. (2021). The impact of regulation on innovation. Technical report, National Bureau of Economic Research.

Atkeson, A. and Burstein, A. (2010). Innovation, firm dynamics, and international trade. Journal of Political Economy, 118(3):433-484.

Axtell, R. L. (2001). Zipf distribution of u.s. firm sizes. Science, 293(5536):1818-1820.

Banerjee, A. and Duflo, E. (2005). Growth theory through the lens of development economics. Handbook of Economic Growth.

Bartelsman, E., Haltiwanger, J., and Scarpetta, S. (2013). Cross-country differences in productivity: The role of allocation and selection. The American Economic Review, 103(1):305-334.

Bello, O., Blyde, J., and Restuccia, D. (2011). Venezuela's growth experience. Latin american journal of economics, 48(2):199-226.

Benhabib, J., Perla, J., and Tonetti, C. (2014). The growth dynamics of innovation, diffusion, and the technology frontier. manuscript,New York University.

Bento, P. and Restuccia, D. (2017). Misallocation, establishment size, and productivity. American Economic Journal: Macroeconomics, 9(3):267-303.

Bento, P. and Restuccia, D. (2021). On average establishment size across sectors and countries. Journal of Monetary Economics, 117:220-242.

Bhattacharya, D., Guner, N., and Ventura, G. (2013). Distortions, endogenous managerial skills and productivity differences. Review of Economic Dynamics, 16(1):11-25.

Buera, F., Moll, B., and Shin, Y. (2013). Well-intended policies. Review of Economic Dynamics, $16(1): 216-230$.

Buera, F. and Oberfield, E. (2014). The global diffusion of ideas. manuscript, Princeton University.

Buera, F. J. and Fattal Jaef, R. N. (2018). The dynamics of development: Innovation and reallocation. World Bank Policy Research Working Paper, (8505).

Bustos, P. (2011). Trade liberalization, exports, and technology upgrading: Evidence on the impact of mercosur on argentinian firms. The American economic review, 101(1):304-340.

Cirera, X., Fattal-Jaef, R., and Maemir, H. (2020). Taxing the good? distortions, misallocation, and productivity in sub-saharan africa. The World Bank Economic Review, 34(1):75-100.

Da-Rocha, J. M. and Pujolas, P. (2011). Policy distortions and aggregate productivity: The role of idiosyncratic shocks. The BE Journal of Macroeconomics, 11(1). 
Da-Rocha, J.-M., Restuccia, D., and Tavares, M. M. (2019). Firing costs, misallocation, and aggregate productivity. Journal of Economic Dynamics and Control, 98:60-81.

David, J. M. and Venkateswaran, V. (2019). The sources of capital misallocation. American Economic Review, 109(7):2531-67.

Davis, S., Haltiwanger, J., and Schuh, S. (1998). Job Creation and Destruction, volume 1 of MIT Press Books. The MIT Press.

di Giovanni, J. and Levchenko, A. A. (2013). Firm entry, trade, and welfare in zipf's world. Journal of International Economics, 89(2):283 - 296.

Fattal Jaef, R. N. (2018). Entry and exit, multiproduct firms, and allocative distortions. American Economic Journal: Macroeconomics, 10(2):86-112.

Gabaix, X. (2009). Power laws in economics and finance. Annual Review of Economics, 1(1):255294.

Gabaix, X. (2016). Power laws in economics: An introduction. Journal of Economic Perspectives, 30(1):185-206.

Gabler, A. and Poschke, M. (2013). Experimentation by firms, distortions, and aggregate productivity. Review of Economic Dynamics, 16(1):26-38.

Gourio, F. and Roys, N. (2014). Size-dependent regulations, firm size distribution, and reallocation. Quantitative Economics, 5:377-416.

Guner, N., Parkhomenko, A., and Ventura, G. (2018). Managers and productivity differences. Review of Economic Dynamics, 29:256-282.

Guner, N., Ventura, G., and Xu, Y. (2008). Macroeconomic implications of size-dependent policies. Review of Economic Dynamics, 11(4):721-744.

Hall, R. and Jones, C. (1999). Why do some countries produce so much more output per worker than others? Quarterly Journal of Economics, pages 83-116.

Hopenhayn, H. (1992). Entry, exit, and firm dynamics in long run equilibrium. Econometrica, 60:1127-50.

Hopenhayn, H. (2014a). Firms, misallocation, and aggregate productivity: A review. Annu. Rev. Econ., 6(1):735-770.

Hopenhayn, H. A. (2014b). On the measure of distortions. Technical report, National Bureau of Economic Research.

Hsieh, C. and Klenow, P. (2009). Misallocation and manufacturing tfp in china and india. Quarterly Journal of Economics, 124(4):1403-1448.

Hsieh, C.-T. and Klenow, P. J. (2014). The life cycle of plants in india and mexico. The Quarterly Journal of Economics, 129(3):1035-1084. 
Klenow, P. and Rodriguez-Clare, A. (1997). The neoclassical revival in growth economics: Has it gone too far? In Bernanke, B. and Rotemberg, J., editors, NBER Macroeconomics Annual. MIT Press, Cambridge.

Lucas, R. and Moll, B. (2014). Knowledge growth and the allocation of time. Journal of Political Economy, 122(1):1-51.

Luttmer, E. (2007). Selection, growth, and the size distribution of firms. Quarterly Journal of Economics, 122(3):1103-1144.

McKenzie, D. and Paffhausen, A. L. (2019). Small firm death in developing countries. Review of economics and statistics, 101(4):645-657.

Pavcnik, N. (2002). Trade liberalization, exit, and productivity improvements: Evidence from chilean plants. The Review of Economic Studies, 69:245-276.

Peters, M. (2020). Heterogeneous markups, growth, and endogenous misallocation. Econometrica, 88(5):2037-2073.

Prescott, E. C. (1998). Needed: A theory of total factor productivity. International Economic Review, 39:525-52.

Ranasinghe, A. (2014). Impact of policy distortions on firm-level innovation, productivity dynamics and tfp. Journal of Economic Dynamics and Control.

Restuccia, D. (2013a). Factor misallocation and development. In Edition, O., editor, The New Palgrave Dictionary of Economics. Steven N. Durlauf and Lawrence E. Blume, Palgrave Macmillan.

Restuccia, D. (2013b). The latin american development problem: An interpretation. Economía, 13(2):69-100.

Restuccia, D. and Rogerson, R. (2008). Policy distortions and aggregate productivity with heterogeneous establishments. Review of Economic Dynamics, 11(4):707-720.

Restuccia, D. and Rogerson, R. (2013). Misallocation and productivity. Review of Economic Dynamics, 16(1):1-10.

Restuccia, D. and Rogerson, R. (2017). The causes and costs of misallocation. Journal of Economic Perspectives, 31(3):151-74.

Rubini, L. (2014). Innovation and the trade elasticity. Journal of Monetary Economics, 66:32-46.

Tybout, J. (2014). The missing middle, revisited. Journal of Economic Perspectives, 28(4):235-36. 


\section{Appendix}

\section{A Proofs}

This appendix presents the proofs of Lemma 1 and Lemma 2, and the characterization of the distribution of TFPR.

\section{A.1 Proof Lemma 1}

From the first order condition for the productivity drift in equation (7), we can solve for the productivity drift $\mu_{z}$ as a function of the determinants of costs and benefits such as distortions $\tau$, cost scale $c_{\mu}$, and the marginal present value profits $W_{z}^{\prime}$. In particular, equating the marginal cost and benefit from productivity growth implies,

$$
\frac{c_{\mu}}{\bar{s}}(z \tau)^{\theta} \mu_{z}^{\theta-1}=z W_{z}^{\prime} .
$$

By guessing and verifying, we find that the optimal Hamilton-Jacobi-Bellman equation is given by $W(z, \tau)=A(w, r) z^{\theta} \tau^{\theta}$, where the constant $A(w, r)$ is the solution of the polynomial:

$$
\begin{array}{r}
{\left[\frac{(\lambda+R)}{(\theta-1)}-\frac{\theta \mu_{\tau}}{(\theta-1)}-\frac{\theta^{2} \sigma_{z} \sigma_{\tau} \rho}{(\theta-1)}-\frac{\theta\left(\sigma_{z}^{2}+\sigma_{\tau}^{2}\right)}{2}\right] A(w, r)} \\
-\left[\frac{\theta \bar{s}}{c_{\mu}}\right]^{\frac{1}{\theta-1}} A(w, r)^{\frac{\theta}{\theta-1}}=\frac{m(w, r)}{(\theta-1)}
\end{array}
$$

After this simplification, we rewrite equation (A.1) finding the following expression for $A(w, r)$ :

$$
A(w, r)=\frac{m(w, r)}{\lambda+R-\theta \mu_{\tau}-\theta^{2} \sigma_{z} \sigma_{\tau} \rho-\frac{\theta(\theta-1)}{2}\left(\sigma_{z}^{2}+\sigma_{\tau}^{2}\right)-(\theta-1) \mu_{z}}
$$

where $\mu_{z}$ depends on $A(w, r)$. Given the solution to this polynomial, the optimal productivity drift 
$\mu_{z}$ is independent of establishment characteristics $\tau$ and $z$ :

$$
\mu_{z}=\left[\frac{\theta A(w, r) \bar{s}}{c_{\mu}}\right]^{\frac{1}{\theta-1}}
$$

\section{A.2 Proof Lemma 2}

After some algebraic manipulation from equation (12), we find that the stationary distribution must satisfy the following differential equation:

$$
f^{\prime \prime}(x)-\frac{2 \mu_{x}}{\sigma_{x}^{2}} f^{\prime}(x)-\frac{2 \lambda}{\sigma_{x}^{2}} f(x)=-\frac{2 b}{\sigma_{x}^{2}} \delta(x-0),
$$

subject to the boundary conditions and $f(\cdot)$ being a pdf. Therefore, the stationary pdf is the solution of the boundary-value problem that consists of solving

$$
\begin{array}{lll}
f^{\prime \prime}(x)-\gamma_{1} f^{\prime}(x)-\gamma_{2} f(x)=0 & \text { if } & x \neq 0, \\
f^{\prime \prime}(x)-\gamma_{1} f^{\prime}(x)-\gamma_{2} f(x)=-\gamma_{3} \delta(x-0) & \text { if } & x=0,
\end{array}
$$

where the constants $\gamma_{1}, \gamma_{2}$, and $\gamma_{3}$ are given by

$$
\gamma_{1}=\frac{2 \mu_{x}}{\sigma_{x}^{2}}<0, \quad \gamma_{2}=\frac{2 \lambda}{\sigma_{x}^{2}}>0, \quad \gamma_{3}=\frac{2 \hat{b}}{\sigma_{x}^{2}}>0 .
$$

We solve the boundary-value problem using Laplace transforms. Laplace transforms are given by

$$
\begin{aligned}
& \mathscr{L}\left[f^{\prime}(x)\right]=s \mathscr{L}[f(x)]-f(0), \\
& \mathscr{L}\left[f^{\prime \prime}(x)\right]=s^{2} \mathscr{L}[f(x)]-s f(0)-f^{\prime}(0) .
\end{aligned}
$$

By applying Laplace transforms in equation (12), we obtain:

$$
\left(s^{2}-\gamma_{1} s-\gamma_{2}\right) \mathscr{L}[f(x)]-\left(s-\gamma_{1}\right) f(0)-f^{\prime}(0)=-\gamma_{3} \mathscr{L}[\delta(x-0)] .
$$


Using the boundary condition $f(0) \geq 0$ and $\mathscr{L}[\delta(x-0)]=1$ we find:

$$
\left(s^{2}-\gamma_{1} s-\gamma_{2}\right) Y(s)=f^{\prime}(0)+\left(s-\gamma_{1}\right) f(0)-\gamma_{3}
$$

where

$$
Y(s)=\frac{f^{\prime}(0)-\gamma_{3}+\left(s-\gamma_{1}\right) f(0)}{\left(s^{2}-\gamma_{1} s-\gamma_{2}\right)}
$$

We obtain the solution by solving the Laplace inverses when $x \neq 0$ given by:

$$
\begin{aligned}
\mathscr{L}^{-1}\left[\frac{1}{\left(s-r_{1}\right)\left(s-r_{2}\right)}\right] & =\frac{1}{\left(r_{1}-r_{2}\right)}\left(e^{r_{1} x}-e^{r_{2} x}\right) \\
\mathscr{L}^{-1}\left[\frac{\left(s-\gamma_{1}\right)}{\left(s-r_{1}\right)\left(s-r_{2}\right)}\right] & =\frac{1}{\left(r_{1}-r_{2}\right)}\left[\left(r_{1}-\gamma_{1}\right) e^{r_{1} x}-\left(r_{2}-\gamma_{1}\right) e^{r_{2} x}\right],
\end{aligned}
$$

where the two roots (one positive and one negative) are given by $r=\frac{\gamma_{1} \pm \sqrt{\gamma_{1}^{2}+4 \gamma_{2}}}{2}$. We can rewrite the final solution for this case as:

$$
\begin{aligned}
& f(x)=\frac{f^{\prime}(0)}{\left(r_{1}-r_{2}\right)}\left(e^{r_{1} x}-e^{r_{2} x}\right)+\frac{f(0)}{\left(r_{1}-r_{2}\right)}\left[\left(r_{1}-\gamma_{1}\right) e^{r_{1} x}-\left(r_{2}-\gamma_{1}\right) e^{r_{2} x}\right] \quad \text { if } \quad x \neq 0, \\
& f(x)=\frac{f^{\prime}(0)-\gamma_{3}}{\left(r_{1}-r_{2}\right)}\left(e^{r_{1} x}-e^{r_{2} x}\right)+\frac{f(0)}{\left(r_{1}-r_{2}\right)}\left[\left(r_{1}-\gamma_{1}\right) e^{r_{1} x}-\left(r_{2}-\gamma_{1}\right) e^{r_{2} x}\right] \quad \text { if } \quad x=0 .
\end{aligned}
$$

When $x \neq 0$ (that is $\forall x \in(-\infty, 0) \cup(0, \infty))$, we have

$$
f(x)= \begin{cases}C_{1} e^{r_{1} x}+C_{2} e^{r_{2} x}, & \text { if } \quad x<0, \\ C_{1} e^{r_{1} x}+C_{2} e^{r_{2} x}, & \text { if } \quad x>0,\end{cases}
$$

where

$$
\begin{aligned}
& C_{1}=\frac{1}{\left(r_{1}-r_{2}\right)}\left[f^{\prime}(0)+f(0)\left(r_{1}-\gamma_{1}\right)\right], \\
& C_{2}=\frac{-1}{\left(r_{1}-r_{2}\right)}\left[f^{\prime}(0)+f(0)\left(r_{2}-\gamma_{1}\right)\right],
\end{aligned}
$$


and $r_{1}>0$ and $r_{2}<0$. When $x>0$ in order to $f(\cdot)$ be a pdf, it is necessary that $C_{1}=0$ and

$$
f^{\prime}(0)=-f(0)\left(r_{1}-\gamma_{1}\right) \Rightarrow C_{2}=\frac{-1}{\left(r_{1}-r_{2}\right)}\left[f(0)\left(\gamma_{1}-r_{1}\right)+f(0)\left(r_{2}-\gamma_{1}\right)\right]=f(0)
$$

Symmetrically when $x<0$ we need $C_{2}=0$. Therefore,

$$
f^{\prime}(0)=-f(0)\left(r_{2}-\gamma_{1}\right) \Rightarrow C_{1}=\frac{1}{\left(r_{1}-r_{2}\right)}\left[f(0)\left(\gamma_{1}-r_{2}\right)+f(0)\left(r_{1}-\gamma_{1}\right)\right]=f(0)
$$

and

$$
f(x)=\left\{\begin{array}{lll}
f(0) e^{r_{1} x} & \text { if } \quad x<0, \\
f(0) e^{r_{2} x} & \text { if } \quad x \geq 0
\end{array}\right.
$$

where $f(0)=\left(\frac{r_{1} r_{2}}{r_{2}-r_{1}}\right)$. Finally we need to prove that: 1) for $x>0, f^{\prime}(0)=-f(0)\left(r_{1}-\gamma_{1}\right)$ (i.e. $C_{1}=0$ ), and 2) for $x<0, f^{\prime}(0)=-f(0)\left(r_{2}-\gamma_{1}\right)$ (i.e. $C_{2}=0$ ); Given that when $x>0$ $f^{\prime}(0)=r_{2} f(0)$ (and when $\left.x<0 f^{\prime}(0)=r_{1} f(0)\right)$ this is equivalent to show that

$$
\left(r_{2}+r_{1}\right) f(0)=\left(\frac{\gamma_{1}-\sqrt{\gamma_{1}^{2}+4 \gamma_{2}}}{2}+\frac{\gamma_{1}+\sqrt{\gamma_{1}^{2}+4 \gamma_{2}}}{2}\right) f(0)=f(0) \gamma_{1}
$$

When $x=0$ we have

$$
f(x)=C_{1} e^{r_{1} x}+C_{2} e^{r_{2} x},
$$

where

$$
\begin{aligned}
& C_{1}=\frac{1}{\left(r_{1}-r_{2}\right)}\left[f^{\prime}(0)-\gamma_{3}+f(0)\left(r_{1}-\gamma_{1}\right)\right], \\
& C_{2}=\frac{-1}{\left(r_{1}-r_{2}\right)}\left[f^{\prime}(0)-\gamma_{3}+f(0)\left(r_{2}-\gamma_{1}\right)\right] .
\end{aligned}
$$


Therefore

$$
f(0)=C_{1}+C_{2}=\frac{1}{\left(r_{1}-r_{2}\right)}\left[r_{1} f(0)-r_{2} f(0)\right]=f(0) .
$$

Using $s=s_{e} e^{x}$, we can recover the size distribution $g(s)$. That is

$$
g(s)=\frac{1}{s} f\left(\ln \left(s / s_{e}\right)\right)=\left\{\begin{array}{l}
f(0) \frac{s^{r_{1}-1}}{s_{e}^{r_{1}}} \quad \text { if } \quad s<s_{e}, \\
f(0) \frac{s^{r_{2}-1}}{s_{e}^{r_{2}}} \quad \text { if } s \geq s_{e} .
\end{array}\right.
$$

Note that this solution is equivalent to the guess and verify solution obtained by solving the characteristic equation $\frac{\sigma_{x}^{2}}{2} \xi^{2}+\left(\mu_{s}-\frac{\sigma_{x}^{2}}{2}\right) \xi-\lambda=0$ with $r_{1}=-\xi_{s}^{-}$and $r_{2}=-\xi_{s}^{+}$.

Finally, average establishment size $\bar{s}$ is given by

$$
\bar{s}=s_{e} \frac{-\xi_{s}^{-} \xi_{s}^{+}}{\left(\xi_{s}^{+}-1\right)\left(1-\xi_{s}^{-}\right)}=s_{e}\left(\frac{\lambda}{\lambda-\mu_{s}}\right)
$$

\section{A.3 TFPR}

In our model, an establishment's TFPR is given by:

$$
\mathrm{TFPR}=\frac{y}{k^{\alpha /(\alpha+\gamma)} n^{\gamma /(\alpha+\gamma)}} \propto \frac{1}{\tau^{\theta(1-\alpha-\gamma)}}=\frac{1}{\left(1-\tau_{y}\right)},
$$

which is equated across all establishments in the undistorted economy. In this context, misallocation arises from dispersion in TFPR across establishments. In our environment, the distribution of distortions $g_{\tau}(\tau)$ is a Double Pareto. Therefore, $\log$ TFPR follows a Double Exponential with roots $\xi_{T F P R,-}$ and $\xi_{T F P R,+}$ that solve the characteristic equation:

$$
\frac{\sigma_{T F P R}^{2}}{2} \xi^{2}+\left(\mu_{T F P R}-\frac{\sigma_{T F P R}^{2}}{2}\right) \xi-\lambda=0,
$$


where $\mu_{T F P R}=-\theta(1-\alpha-\gamma) \mu_{\tau}-\theta(1-\alpha-\gamma)(-\theta(1-\alpha-\gamma)-1) \frac{\sigma_{\tau}^{2}}{2}$ and $\sigma_{T F P R}^{2}=\theta^{2}(1-\alpha-\gamma)^{2} \sigma_{\tau}^{2}$. Standard deviation of $\log$ revenue total factor productivity (TFPR):

$$
\mathrm{SD} \log \mathrm{TFPR}=\sqrt{\frac{1}{\xi_{T F P R,-}^{2}}+\frac{1}{\xi_{T F P R,+}^{2}}} .
$$

\section{B Model Extension}

We extend the model to allow for the mass of establishments to be determined in equilibrium and assess how our main results change in this case. We first highlight changes in the solution of the model with endogenous mass of establishments, and then we show quantitatively how the results change in this extended model.

Potential entering establishments face an entry cost $c_{e}$ in units of output and make their entry decision knowing the entry distortion $\tau_{e}$. For tractability, we assume that entrants start with the same level of productivity, denoted by $z_{e}$. The initial level of productivity is such that the value of entering establishments satisfies the zero profit condition:

$$
W_{e}=A(w, r)\left(\tau_{e} z_{e}\right)^{\theta}-c_{e}=A(w, r) s_{e}-c_{e}=0
$$

Note that such a value of productivity $z_{e}$ exists and is unique which follows from the fact that the value of entry $W_{e}$ inherits the properties of the value of incumbent establishments which is increasing in productivity $z_{e}$.

To find the stationary distribution, we proceed by following a similar methodology as in the main text. Given the optimal decisions of incumbents and entering establishments, we characterize the stationary distribution $g(z, \tau)$ over productivity $z$ and distortion $\tau$. Let $\Phi(x, t)$ denote the number

of establishments of size $x$ at time $t$. At time $t, \Phi(t)=\int_{-\infty}^{+\infty} \Phi(x, t) d x$. The establishments relative size process can be modeled by a modified Kolmogorov-Fokker-Planck equation of the form:

$$
\frac{\partial \Phi(x, t)}{\partial t}=-\mu_{x} \frac{\partial \Phi(x, t)}{\partial x}+\frac{\sigma_{x}^{2}}{2} \frac{\partial^{2} \Phi(x, t)}{\partial x^{2}}-\lambda \Phi(x, t)+B(0, t)
$$

where $\lambda$ is the exit rate of establishments and the function $B(0, t)$ is new establishments that enter 
at $t$.We are interested in a stationary distribution for the number density function, i.e. solutions that are separable in time $t$ and are of the form $\Phi(x, t)=N f(x)$ and $B(0, t)=\left(\int_{0}^{+\infty} f_{\infty}(x) d s\right) B(0)$. Assuming that

$$
N\left(\int_{0}^{+\infty} f_{\infty}(x) d s\right)=1
$$

we can rewrite the modified Kolmogorov-Fokker-Planck equation equation (B.4) as:

$$
\frac{N^{\prime}(t)}{N} f(x)=0=-\mu_{x} f^{\prime}(x)+\frac{\sigma_{x}^{2}}{2} f^{\prime \prime}(x)-\lambda f(x)+b \delta(x-0)=0
$$

which is a similar to equation (12) in the main text. Given $N=\left(\frac{\xi_{s}^{+}-\xi_{s}^{-}}{-\xi_{s}^{-}}\right)$, labor and capital market clearing conditions depend on the number of establishments:

$$
K=N \int_{0}^{+\infty} k(s) g(s) d s
$$

and

$$
1=N \int_{0}^{+\infty} n(s) g(s) d s
$$

Therefore aggregate output $Y$ and total factor productivity TFP explicitly depend on the mass of establishments $N$ as shown in the equations below:

$$
\begin{aligned}
Y & =\left(\frac{\alpha}{r}\right)^{\frac{\alpha}{1-\alpha}}\left(\frac{\lambda-\mu_{s}}{\lambda-\mu_{y}}\right)(N \bar{s})^{\frac{1-\alpha-\gamma}{1-\alpha}}\left(\frac{1}{\tau_{e}^{\theta(1-\alpha-\gamma)}}\right), \\
\mathrm{TFP} & =\left(\frac{\lambda-\mu_{s}}{\lambda-\mu_{y}}\right)(N \bar{s})^{1-\alpha-\gamma}\left(\frac{1}{\tau_{e}^{\theta(1-\alpha-\gamma)}}\right) .
\end{aligned}
$$

Following these modifications, we present new results for an economy with endogenous mass of establishments.

We assess quantitatively how the model predictions change when we introduce the mass of establishments endogenously. We depart from our calibrated economy, where the mass is exogenous and normalized to one, compute the impact on TFP in the model with and without an endogenous mass of establishments, and where $\xi_{s}$ varies or it is constant.

Table 2 presents the main results. When the mass is endogenous, the impact of policy distortions 
Table 2: Impact of Endogenous Mass of Establishments

\begin{tabular}{lccc}
\hline$\sigma_{\tau}$ & 0.39 & 0.41 & 0.42 \\
\hline Exogenous Mass & & & \\
TFP baseline & 1.00 & 0.81 & 0.76 \\
TFP $\xi$ constant & 1.00 & 0.71 & 0.65 \\
\hline Endogenous Mass & & & \\
TFP baseline & 1.00 & 0.83 & 0.78 \\
TFP $\xi$ constant & 1.00 & 0.74 & 0.68 \\
\hline
\end{tabular}

is reduced because more firms enter the distorted economy, which offsets some of the impacts of the increase in policy distortions. This effect is well-documented in the literature, see Fattal Jaef (2018) and Bento and Restuccia (2021). The increase in the number of firms entering reduces the impact of policy distortions. The same intuition holds for an economy where $\xi_{s}$ is constant. 